\title{
ELABORAÇÃO DE SEQUÊNCIA DIDÁTICA PARA ENSINO DE INGLÊS A UMA CRIANÇA COM NECESSIDADES EDUCACIONAIS ESPECIAIS
}

\author{
Otto Henrique Silva Ferreira (G-UEL/IC-CNPQ) \\ Profa. Dra. Juliana Reichert Assunção Tonelli (UEL/PPGEL/MEPLEM)
}

\section{RESUMO}

Este trabalho consiste na análise do desenvolvimento e da aplicação de uma sequência didática (SD) vinculada ao gênero textual "história infantil" para o ensino de inglês a uma criança com autismo, ao mesmo tempo proporcionado além de sua inclusão, sua integração no ambiente escolar. $O$ ensino da língua inglesa para crianças com necessidades educacionais especiais (NEE) vem sendo cada vez mais posto em foco no Brasil, junto ao fato da língua estar vindo a ser considerada cada vez mais uma "língua universal" (TONELLI, 2012; MONTEIRO, 2013). A utilização da SD como instrumento para o ensino de inglês à criança com NEE visa uma conexão entre o ensino da língua, de maneira estratégica e sistemática, e o desenvolvimento das capacidades orais e escritas do aluno (SCHNEUWLY; DOLZ, 2004), além da viabilidade da ferramenta para a criação de contextos de comunicação que proporcionam a aprendizagem (GONÇALVES; FERRAZ, 2014). A SD foi aplicada em uma sala do nível E5 do Centro de Educação Infantil da Universidade Estadual de Londrina, para 15 alunos, um deles com o diagnóstico do transtorno do espectro autista. A produção final de todos os alunos alcançou os objetivos pré-determinados na elaboração da sequência.

Palavras-chave: ensino de inglês, sequência didática, educação especial.

\section{INTRODUÇÃO}

Este trabalho foi desenvolvido objetivando adaptar uma SD a fim de melhorar a qualidade de ensino da língua inglesa (LI) a um aluno (L) com transtorno do espectro autista (TEA), em grau definido como severo pela equipe de psicólogos e psiquiatras que o acompanha, integrante de uma turma composta por alunos de 5 e 6 anos de idade, por meio da utilização do gênero história infantil (HI) e da SD como organizadora de atividades, esperando que a mesma auxilie na compreensão da LI mediante criação de contextos de comunicação, nos quais seria possível trabalhar a língua por meio de gêneros textuais e facilitar, assim, a compreensão e o engajamento do aluno em atividades de sala de aula. A necessidade da busca por diferentes métodos para o ensino da LI foi vista em função da análise de algumas atividades em que, quando o aluno dedicava-se a resolução, não alcançava o resultado esperado pelos professores * .

$\mathrm{O}$ artigo está organizado em quatro partes, durante as quais buscamos responder ao questionamento: é possível melhorar a qualidade de ensino a uma criança com NEE através da aplicação de uma SD? Na primeira parte explicitamos a justificativa, a

\footnotetext{
* A aplicação da SD foi realizada em um Centro de Educação Infantil na cidade de Londrina, Paraná, por professores estagiários graduandos da Universidade Estadual de Londrina, no ano de 2015.
} 


\section{SEMINÁRIO DE PESQUISA EM CIÊNCIAS HUMANAS - SEPECH \\ Humanidades, Estado e desafios didático-científicos \\ Londrina, 27 a 29 de julho de 2016}

motivação para o desenvolvimento do trabalho e os objetivos da sua realização. Na segunda focamos as discussões e as reflexões acerca das quais a fundamentação teórica é apresentada. Nestas, abordamos brevemente as definições de SD e NEE, explicamos o que é o TEA e o que o diagnóstico representa para o indivíduo e, por fim, o ensino de inglês a crianças com TEA. Na terceira, explicitamos os procedimentos metodológicos para a realização da pesquisa. Por fim, apresentamos as considerações finais.

\section{JUSTIFICATIVA}

A firmação da Lei $\mathrm{n}^{\circ} 12.764$ (BRASIL, 2012) dispõe sobre a política nacional de proteção dos direitos das pessoas com transtorno do espectro autista, reafirma o direito a educação, e garante que todos têm o direito de aprender. Existem inúmeros indivíduos cursando o ensino infantil que diferem entre si na forma de aprendizagem e existem aqueles que necessitam de uma educação especial, grupo em que se enquadram os autistas. Essas diferenças são enfatizadas em muitos documentos e leis brasileiras, como é possível observar na Declaração de Salamanca (1997, p. 1):

Toda criança possui características, interesses, habilidades e necessidades de aprendizagem que são únicas. Sistemas educacionais deveriam ser designados e programas educacionais deveriam ser implementados no sentido de se levar em conta a vasta diversidade de tais características e necessidades.

Com o aumento da demanda do ensino de inglês nas escolas públicas, vem crescendo também a área de ensino da língua para crianças e, consecutivamente, para crianças com NEE. É destacado por alguns autores (ROCHA e TONELLI, 2013; SILVEIRA, SANTOS e SILVA, 2015; ROCHA, 2016) o processo de inclusão desses alunos nas redes de ensino regular, afirmando também que este fato colabora para um ambiente multifacetado de ensino, criando desafios para os professores e lançando reflexões a respeito das metodologias de ensino utilizadas visando à educação das crianças com NEE, o que abre espaço para discussões e proposições de novas metodologias de ensino. Neste trabalho, a proposta da utilização da SD para o ensino de LI para crianças, incluindo a uma criança com TEA é embasada por autores que demonstram eficácia nos resultados das produções finais dos alunos (PETRECHE, 2008; TONELLI, 2012), além de pesquisadores que respaldam a utilização da SD para o ensino de línguas, apontando-a como um "megainstrumento" viável para o desenvolvimento do aluno em suas capacidades de comunicação oral e escrita (SCHNEUWLY e DOLZ, 2004; GONÇALVES e FERRAZ, 2014).

O objetivo geral de pesquisa é adaptar uma SD do gênero HI produzida para o ensino de inglês a uma sala com crianças de 5 a 6 anos, acrescentando atividades e instruções que favoreçam a inclusão e a participação de crianças com NEE, no caso, TEA.

Mais especificamente:

- Observar a criança durante a realização das atividades da SD;

- Realizar adaptações e modificações nas atividades quando necessário;

- Avaliar o progresso da criança após a realização das atividades; 


\section{SEMINÁRIO DE PESQUISA EM CIÊNCIAS HUMANAS - SEPECH \\ Humanidades, Estado e desafios didático-científicos \\ Londrina, 27 a 29 de julho de 2016}

- Realizar uma produção final para demonstração de resultados.

\section{FUNDAMENTAÇÃO TEÓRICA}

\subsection{Sequência Didática}

Dolz, Noverraz e Schneuwly (2004) definem SD como uma série de atividades escolares organizadas sistematicamente em torno de um gênero discursivo, podendo ser este textual, oral ou escrito. A utilização dessa ferramenta é tida pelos autores como ideal se objetivando possibilitar aos alunos o ensino e a prática de linguagens novas ou dificilmente domináveis, definição esta na qual podemos igualmente encaixar o ensino de línguas estrangeiras (CRISTOVÃO, 2001; CRISTOVÃO, 2009).

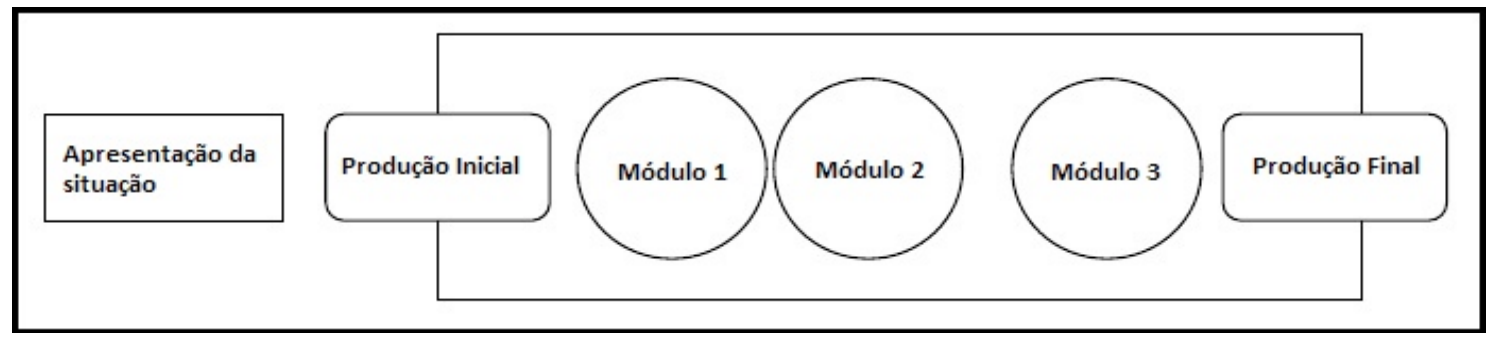

Figura 1 - Esquema de Sequência Didática

Fonte: Dolz, Noverraz e Schneuwly (2004, p. 98).

$\mathrm{Na}$ apresentação da situação, é exposto aos alunos o gênero que será trabalhado na SD e o projeto de classe que norteará a produção final dos estudantes, motivando o trabalho e estimulando a busca pelo domínio das capacidades e técnicas que a SD buscar desenvolver. A produção inicial serve para diagnosticar o conhecimento prévio do aluno a respeito do gênero. Os módulos são preparados de acordo com as características do gênero, sendo divididos de maneira a possibilitar a capacitação do aluno na utilização do mesmo. A produção final é importante para que seja observada a evolução do aluno, a efetividade ou não do processo de ensino/aprendizagem.

Amaral (2014) afirma que as SDs podem e devem ser utilizadas para o ensino de qualquer disciplina ou conteúdo, apresentando como argumento o fato de as mesmas auxiliarem o professor no processo de organização de seu trabalho em sala de aula e apresentarem um formato que favorece a progressão gradual, partindo de níveis de conhecimento que os alunos já dominam e chegando a níveis que eles devem dominar.

Stutz (2012), por sua vez, aponta as SDs como prescrições, ou seja, conjuntos de atividades prescritas elaboradas por alunos-professores, voltadas às capacidades de linguagem de um determinado gênero, trabalhadas por via de atividades progressivas.

Concluindo e agregando a estes pensamentos, Tonelli (2012) reafirma a necessidade de explorar com os alunos em uma SD gêneros que os mesmos não dominem ou necessitem de uma intervenção voltada ao desenvolvimento de suas capacidades de linguagem. A pesquisadora também faz uso do instrumento em sua tese de doutorado, tendo como sujeito de pesquisa um aluno disléxico e a busca pelo ensinoaprendizagem de LI por esse aluno, o que dá ênfase à questão do ensino de LI a crianças com NEE e que embasa esse trabalho. 


\section{SEMINÁRIO DE PESQUISA EM CIÊNCIAS HUMANAS - SEPECH \\ Humanidades, Estado e desafios didático-científicos \\ Londrina, 27 a 29 de julho de 2016}

\subsection{Necessidades Educacionais Especiais}

Enquadram-se na definição de alunos com NEE aqueles que demandam métodos diferentes de ensino, motivados por alta habilidade ou dificuldade na aprendizagem (MENEZES e SANTOS, 2001). Após a publicação da Declaração de Salamanca (1997), a concepção de NEE deixou de ser restrita às pessoas com deficiência física/mental, passando a incluir também aqueles que não respondem às metodologias de ensino convencionais, necessitando, assim, de direcionamentos específicos e abordagens diferenciadas.

\subsubsection{O Transtorno do Espectro Autista}

Segundo Pennington (1997), o autismo (agora TEA) faz parte de uma lista de distúrbios de aprendizagem que podem afetar primeiramente a cognição social. Desta forma, o diagnóstico implicaria numa capacidade de comunicação prejudicada, limitando as relações sociais do indivíduo afetado pelo mesmo. $\mathrm{O}$ autor coloca o diagnóstico precoce como uma ferramenta pelo fato do tratamento perdurar ao longo da vida, podendo assim, influenciar diretamente na evolução do portador do transtorno.

De acordo com a definição apresentada por Rocha e Tonelli (2013, p. 3), o TEA é um "transtorno global do desenvolvimento, caracterizado por ser uma desordem neurológica que priva o indivíduo de seu desenvolvimento social pleno". Para Silveira, Santos e Silva (2015, p.3) o TEA é "um conjunto de sintomas e dificuldades que causam prejuízo qualitativo na comunicação verbal e interesses restritos de atividades".

Portanto, podemos concluir que o autista é afetado em sua capacidade de comunicação social.

\subsection{O ensino de inglês a crianças com transtorno do espectro autista}

O aluno com TEA, apesar de todas as implicações que o diagnóstico carrega, é um aluno repleto de individualidades. Conforme afirmado por Santos et al. (2013), em se tratando do ensino de crianças com TEA, não é indicado que os professores se prendam às suas habilidades e pontos fortes demonstrados no dia-a-dia em sala de aula, mas sim que procurem trabalhar para que haja uma diminuição de seus limites. Os autores afirmam também que esses alunos, caracteristicamente, dão preferência à realização de atividades visuais e concretas, preterindo atividades estrita e sistematicamente verbais, além de apontarem a figura do professor como algo que pode aumentar ou diminuir as chances de serem promovidas novas aprendizagens, dependendo de suas atitudes em sala de aula.

Sousa, Costa e Castro (2012) trazem à tona a necessidade de se trabalhar com atividades lúdicas, proporcionando também momentos de diversão ao aluno autista, para que a sua atenção seja buscada de maneira eficiente e haja uma influência positiva no desenvolvimento de seu sistema cognitivo e em sua aprendizagem.

Rocha e Tonelli (2013) apontam como imprescindível o ensino de inglês para pessoas com TEA, levadas em conta suas limitações e particularidades. Os autores 


\section{SEMINÁRIO DE PESQUISA EM CIÊNCIAS HUMANAS - SEPECH \\ Humanidades, Estado e desafios didático-científicos \\ Londrina, 27 a 29 de julho de 2016}

afirmam que o desenvolvimento social e cognitivo do indivíduo é fortalecido pela aprendizagem da língua estrangeira.

\section{METODOLOGIA E APLICAÇÃO DA SD}

O gênero escolhido para ser trabalhado com a turma E5 foi HI. Tomando por base BRONCKART (2003) e TONELLI (2005), o mesmo foi identificado como ideal para trabalhar o imaginário e a fantasia das crianças, porém, sem deixar de lado a o ensino da LI. O livro "The Very Hungry Caterpillar" (Eric Carle, 1969) foi escolhido para nortear o trabalho com o gênero após uma análise feita pelo grupo de estágio ${ }^{*}$, observando as características das personagens, as textuais, as imagens e a adequação à turma.

L possui limitações decorrentes do transtorno que prejudicam a sua oralidade num nível severo, mas não a compreensão de comandos diretos. Durante as aulas, o aluno sempre demonstrou grande interesse pelos livros de HI que via na estante da sala de aula, o que também influenciou na escolha do gênero textual e do livro. Sendo assim, propusemos o projeto de classe de expor HIs criadas pelos próprios alunos e baseadas no trabalho decorrente de dois módulos: characters (1) e setting (2) ${ }^{* *}$, durante os quais seriam explorados através de atividades elementos essenciais ao gênero HI, utilizando o livro The Very Hungry Caterpillar como texto base.

$\mathrm{Na}$ primeira aula de aplicação da SD, explicamos aos alunos o projeto de classe e a ideia de que produzissem uma HI ao fim das aulas. Após a leitura do livro, foi pedido aos alunos que fizessem uma produção inicial, na qual deveriam reproduzir a história na ordem correta através de colagens. Os alunos foram organizados em grupos de três/quatro para a realização da atividade. L foi incluído em um grupo com outros dois colegas (fig. 1) e, durante a realização da atividade, foi acompanhado de perto pelo pesquisador para que fosse identificado se ele possuía domínio absoluto sobre o gênero HI, ou se seria viável a utilização do mesmo na SD. Apesar da reconstrução da história ter sido executada corretamente, o aluno não soube identificar e apontar os elementos estruturais que definiam o começo, o meio e o fim da história. Tais elementos demonstram-se essenciais ao gênero HI por fazerem parte do que compõe a organização de sequências narrativas, que são apontadas por Tonelli (2005) como predominantes no encadeamento e na organização das sequências discursivas no gênero.

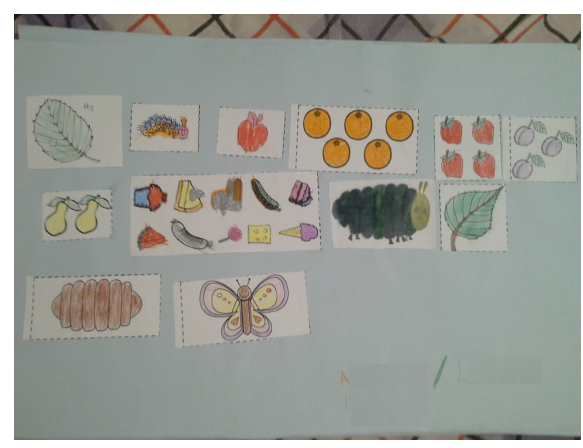

\footnotetext{
* Grupo de estágio composto por alunos graduandos da Universidade Estadual de Londrina, sob orientação da prof ${ }^{\mathrm{a}} \mathrm{Dr}^{\mathrm{a}}$ Juliana Reichert Assunção Tonelli.

${ }^{* *}$ Personagens (1) e configuração/cenário (2).
} 


\section{SEMINÁRIO DE PESQUISA EM CIÊNCIAS HUMANAS - SEPECH \\ Humanidades, Estado e desafios didático-científicos \\ Londrina, 27 a 29 de julho de 2016}

Figura 2 - Produção Inicial do grupo do aluno com TEA

Fonte: os autores.

Após conversas com os alunos e análise dos resultados das produções iniciais, tomando por base as ideias de SCHNEUWLY e DOLZ (2004) e TONELLI (2012), foi constatado que seria viável a utilização de uma SD do gênero HI para o ensino de LI ao aluno com TEA, pois o mesmo não possuía domínio amplo sobre o gênero.

A SD foi aplicada no período de $26 / 10$ a $09 / 12$, dentre o qual a busca foi por trabalhar com atividades que fixassem as características essenciais do gênero HI na LI, enfatizando também o intuito de que as crianças dominassem a linguagem comum do gênero. $O$ desafio, porém, surgia quando as atividades deveriam contemplar as individualidades de cada aluno e, principalmente, do aluno com laudo de TEA. Diante dessa situação, recorremos a Tonelli (2012), Santos et al. (2013) e Rocha e Tonelli (2013) para unir às ideias já existentes relacionadas ao teor das atividades que seriam propostas na SD.

A maior mudança no teor das atividades foi relacionada à ideia de que, a partir de então, todas estariam relacionadas ao livro The Very Hungry Caterpillar e ao gênero HI, estando assim, contextualizadas. A busca foi por deixar L familiarizado com a história, a personagem, o cenário e a ordem da mesma. Além disso, procuramos por uma aproximação direta do pesquisador com o aluno, para que o seu interesse pela aula fosse fortalecido com o passar do tempo. As atividades sempre vinham acompanhadas por imagens e o trabalho realizado privilegiava a utilização de colagens, o que fazia com que L trabalhasse de forma concreta com as figuras e entendesse como cada elemento se encaixava nas situações dentro da história. Diante disso, em algumas atividades nas quais antes o aluno demonstrava um desempenho abaixo do esperado, foi possível verificar uma evolução. Na figura 2, podemos observar uma atividade precedente à sequência, chamada pelas professoras regentes da turma de "desenho livre". A princípio, L recusou-se a pegar o lápis para desenhar, mas, após insistência da professora, ele realizou-a.

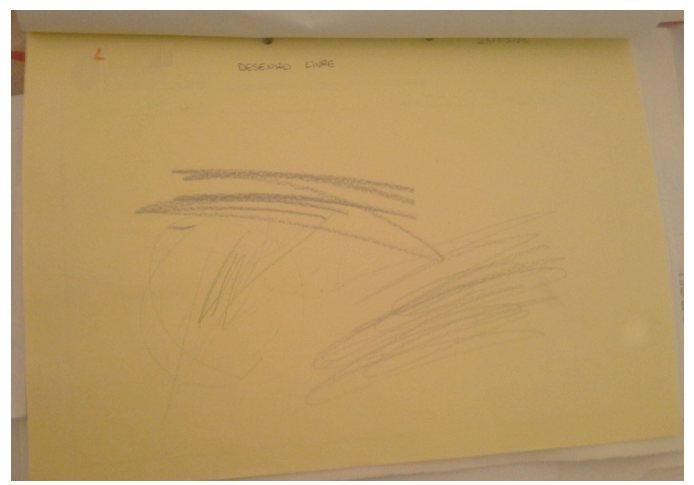

Fig. 3 - Atividade de desenho sem contextualização

Fonte: os autores.

$\mathrm{Na}$ atividade de desenho proposta no módulo 1 da SD, o aluno deveria desenhar o seu animal favorito, que seria o personagem principal de sua história na produção final. $\mathrm{O}$ pesquisador mostrou imagens de animais ao aluno, para que o mesmo pudesse 


\section{SEMINÁRIO DE PESQUISA EM CIÊNCIAS HUMANAS - SEPECH \\ Humanidades, Estado e desafios didático-científicos \\ Londrina, 27 a 29 de julho de 2016}

escolher um. L apontou para o cachorro, e, ao receber a proposta da atividade, não ofereceu resistência alguma ao pesquisador quando este lhe ofereceu os lápis para realização da atividade.

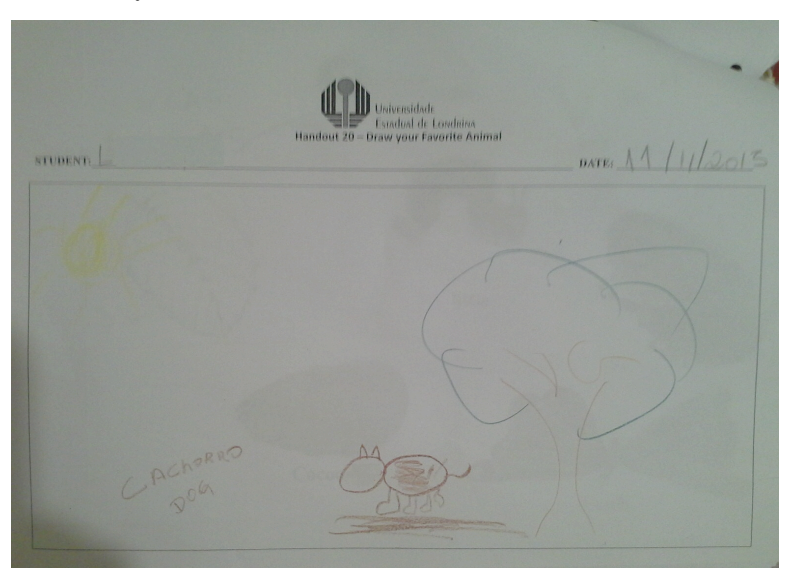

Fig. 4 - Atividade contextualizada de desenho inserida no módulo 1 da SD

Fonte: os autores.

Mais além, no decorrer do módulo 1, o aluno demonstrou ótimo desempenho em atividades que requeriam o uso específico da coordenação motora. Conforme proposto por Sousa, Costa e Castro (2012), as atividades foram propostas de forma lúdica, como por exemplo, na atividade "help the caterpillar to go through the maze and become a butterfly" (fig. 4) de modo que o professor as explicava chamando a atenção de L para as personagens e os desafios que as mesmas teriam que superar, transformando o processo de realizar a atividade em um jogo, cujo propósito maior era ajudar a lagartinha a se tornar uma borboleta, como ocorre na história The Very Hungry Caterpillar.

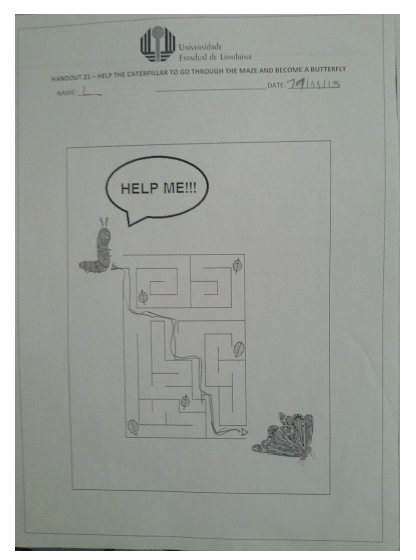

Fig. 5 - Atividade de coordenação motora inserida no módulo 1 da SD

Fonte: os autores.

Após a identificação da preferência de L por atividades que trabalhavam sua coordenação motora, uma relação foi feita com seu ótimo desempenho na realização de 


\section{SEMINÁRIO DE PESQUISA EM CIÊNCIAS HUMANAS - SEPECH \\ Humanidades, Estado e desafios didático-científicos \\ Londrina, 27 a 29 de julho de 2016}

atividades com colagem (fig. 1). Diante dessas análises advindas de observações em sala de aula, foi proposta uma adaptação da produção final individual, que foi organizada de duas maneiras diferentes: uma para L, outra para o restante dos alunos; porém, a decisão de adaptar a proposta de produção final foi tomada apenas com o intuito de respeitar as limitações da criança autista, não alterando os objetivos da produção e a análise de seu desempenho.

Enquanto os outros alunos desenharam e contaram a sua história, identificando characters e setting ${ }^{*}$ e explicando-a utilizando o vocabulário aprendido na língua inglesa, o aluno L reproduziu a história através de colagens, correspondendo à mediação do professor na língua estrangeira e organizando-a conforme o que pensava ser a ordem correta.

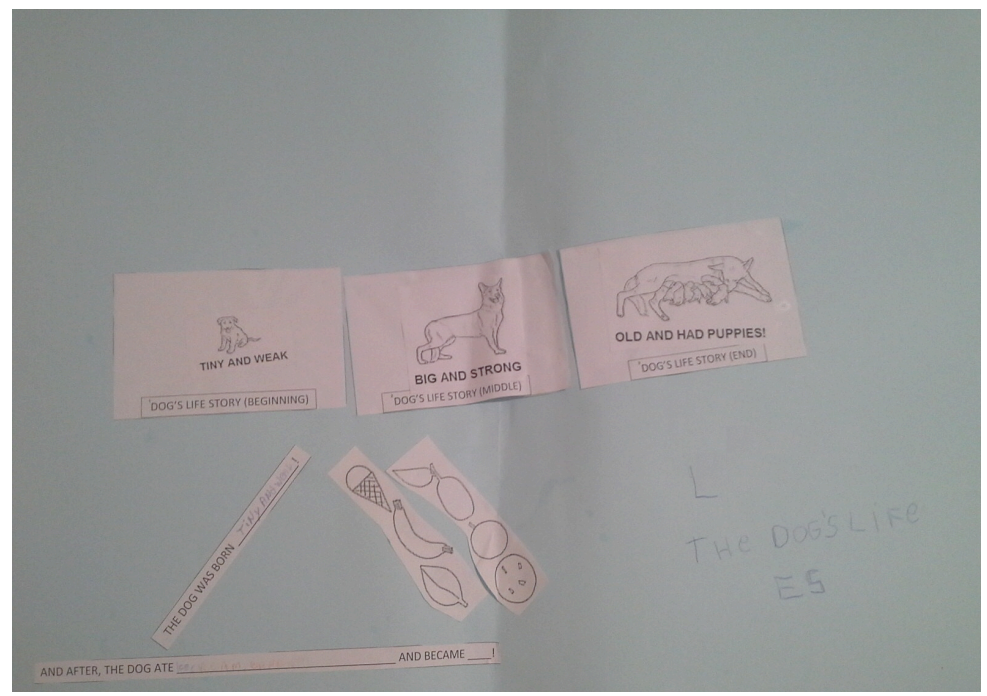

Fig. 6 - Produção final

Fonte: os autores.

Antes de iniciar a produção, foram mostradas ao aluno figuras com diferentes animais: cobra, urso, gato e cachorro. O pesquisador pediu que ele identificasse qual animal ele mais gostava, L apontou para o cachorro e, então, foi iniciada a atividade. Durante a mesma, o pesquisador embaralhou figuras que representavam o cachorro em diferentes fases de sua vida, e pediu ao aluno que as ordenasse de forma coerente, colando-as numa cartolina. O aluno conseguiu identificar as partes da história, começo, meio e fim, corretamente, demonstrando ter adquirido conhecimento a respeito das partes que compõe a história.

\section{CONSIDERAÇÕES FINAIS}

Este artigo foi desenvolvido com o intuito de auxiliar no ensino/aprendizagem de crianças com NEE, no caso, TEA, aprendizes de língua inglesa. Para tanto, buscamos a adaptação da ferramenta SD e, por fim, analisar os resultados de sua aplicação. A SD

\footnotetext{
* Personagens e configuração/cenário.
} 


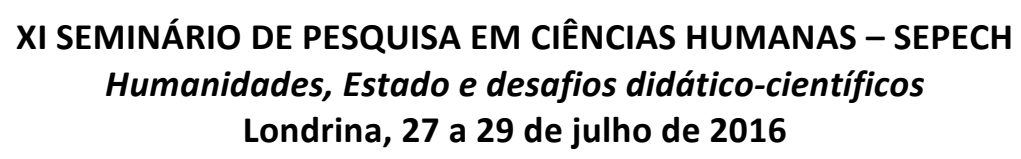

proporcionou ao pesquisador a possibilidade de trabalhar com um leque de atividades lúdicas, contextualizadas pelo gênero $\mathrm{HI}$ e a temática dos módulos, o que favoreceu a aprendizagem do aluno. Foi possível constatar que houve uma evolução da aprendizagem por parte do aluno autista, evidenciada, inclusive, pelos pais em conversa informal. Durante a execução da produção final, verificamos que L conseguiu elaborar uma HI utilizando o conhecimento adquirido durante o trabalho nos dois módulos da SD recebendo instruções por meio do uso restrito da língua inglesa, algo que, antes do trabalho com a SD, seria considerado além de suas limitações.

\section{REFERÊNCIAS}

AMARAL, Heloísa. Sequência didática e ensino de gêneros textuais. 2014. Disponível em: https://www.escrevendoofuturo.org.br/conteudo/biblioteca/artigos/artigo/1539/sequenci a-didatica-e-ensino-de-generos-textuais>. Acesso em: 01 Jun. 2015

BRASIL. Lei $\mathrm{n}^{\circ} 12.764$, de 27 de dezembro de 2012. Dispõe sobre a política nacional de proteção dos direitos das pessoas com transtorno do espectro autista. Disponível em: <http://www.planalto.gov.br/ccivil_03/_ato2011-2014/2012/lei/112764.htm>. Acesso em 13 fev. 2016.

. Declaração de Salamanca: sobre princípios, políticas e práticas na área das necessidades educativas especiais. 1997. Disponível em: $<$ http://portal.mec.gov.br/seesp/arquivos/pdf/salamanca.pdf $>$. Acesso em: 29 jun. 2015.

BRONCKART, J.P. Atividade de linguagem, textos e discurso: por um interacionismo sócio-discursivo. Tradução de Anna Raquel Machado e Péricles Cunha. São Paulo: EDUC, 2003.

CARLE, E. The Very Hungry Caterpillar. United States: Putnam/Philomel, 1969. p.22.

CRISTOVÃO, V. L. L. Gêneros e ensino de leitura em LE: modelos didáticos de gêneros na construção e avaliação de material didático. 2001. Tese (Doutorado em Linguística Aplicada e Estudos da Linguagem) - Pontifícia Universidade Católica de São Paulo, São Paulo: PUC-SP, 2001.

Sequências Didáticas para o Ensino de Línguas. In: Dias, R.; CRISTOVÃO V. L. L. (Orgs.). O livro didático de língua estrangeira: múltiplas perspectivas. Campinas: Mercado de Letras, 2009. p. 305-344.

DOLZ, J.; NOVERRAZ, M.; SCHNEUWLY, B.. Sequências didáticas para o oral e a escrita: apresentação de um procedimento. In: SCHNEUWLY, B. DOLZ, J. Gêneros orais e escritos na escola. Trad. de Roxane Rojo e Glaís Sales Cordeiro. Campinas: Mercado de Letras, 2004. P.95 128. 


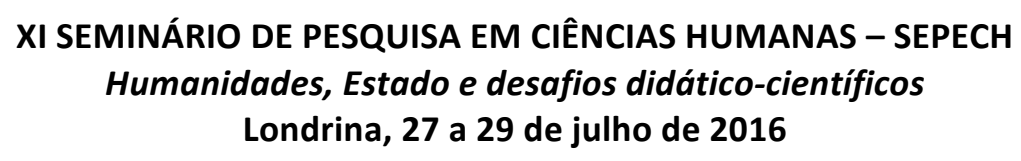

GONÇALVES, A. V.; FERRAZ, M. R. R.. Ferramentas didáticas e ensino: da teoria à prática de sala de aula. In: NASCIMENTO, Elvira Lopes (Org.). Gêneros textuais: da didática das línguas aos objetos de ensino. Campinas, SP: Pontes Editores, 2014.

LANFERDINI, P. A. F.. O trabalho (agir) docente no processo coletivo de planejamento e elaboração de uma sequência didática para o ensino de Língua Inglesa. 2012. 178 f. Dissertação (Mestrado em Estudos da Linguagem) - Universidade Estadual de Londrina, Londrina, 2012.

MENEZES, E. T.; SANTOS, T. H.. Verbete necessidades educacionais especiais. Dicionário Interativo da Educação Brasileira - Educabrasil. São Paulo: Midiamix, 2001. Disponível em: < http://www.educabrasil.com.br/necessidades-educacionais-especiais/>. Acesso em: 11 de mai. 2016.

MONTEIRO, S. I. C. As TIC como recurso pedagógico no ensino do Inglês a crianças com NEE. 2013. 126f. Dissertação (Mestrado em Ciências da Educação) Escola Superior de Educação João de Deus.

PENNINGTON, B. F.. 1946 - Diagnósticos de distúrbios de aprendizagem: um referencial neuropsicológico. São Paulo: Pioneira, 1997.

PETRECHE, C. R. C. A sequência didática nas aulas de língua inglesa do ensino médio e o desenvolvimento de capacidades de linguagem. 2008. 227f. Dissertação (Mestrado em Estudos da Linguagem) - Universidade Estadual de Londrina.

ROCHA, E. P.; TONELli, J. R. A. A Síndrome de Asperger e o Ensino de Língua Inglesa: Possibilidades e Desafios. Revista X/UFPR. Edição Nº. 1, Vol. 1, 2013, p. 3848.

; _. . O autista na sala de aula de Língua Inglesa: um dilema, ou um mundo de oportunidades? REVISTA ELETRÔNICA PRO DOCÊNCIA/UEL. Edição $\mathrm{N}^{\circ}$. 3, Vol. 1, jan-jun. 2013. DISPONÍVEL EM: $<$ http://www.uel.br/revistas/prodocenciafope $>$.

ROCHA, E. P. Possibilidades e desafios na formação de professores de língua inglesa á indivíduos com a Síndrome de Asperger. 2016. 142 f. Dissertação (Mestrado em Estudos da Linguagem) - Universidade Estadual de Londrina, Londrina, 2016.

SANTOS, A. et al. Metodologias de ensino para crianças autistas: superando limitações em busca da inclusão. Anais Fiped V (2013), Edição $\mathrm{N}^{0}$ 2, Vol. 1. DISPONÍVEL

EM:

$<$ http://www.editorarealize.com.br/revistas/fiped/trabalhos/Trabalho_Comunicacao_oral _idinscrito_1695_ee8a90ab371b8e7be05bf467184f1ded.pdf $>$.

SCHNEUWLY, B; DOLZ, J. Gêneros e progressão em expressão oral e escrita elementos para reflexões sobre uma experiência suíça (francófona). In: ROJO, R.; 
CORDEIRO, G. S. (Org. e trad.) Gêneros Orais e Escritos na Escola. São Paulo: Mercado de Letras, 2004, p. 41-70.

SILVEIRA, S. N.; SANTOS, A. J.; SILVA, M. K. A Formação do Professor de Língua Inglesa e o Processo de Inclusão da Criança com Transtorno do Espectro Autista - TEA na Sala de Aula. IV Semana Internacional de Pedagogia; I Seminário Luso-Brasileiro de Educação Infantil, Universidade Federal de Alagoas. 21 a 25 de Novembro de 2015.

SOUSA, F. R. M.; COSTA, E. A. B.; CASTRO, T. H. C. WorldTour: Software para Suporte no Ensino de Crianças Autistas. Anais do $23^{\circ}$ Simpósio Brasileiro de Informática na Educação (SBIE 2012), Rio de Janeiro, 26-30 de Novembro de 2012.

STUTZ, L. Sequências didáticas, socialização de diários e autoconfrontação: instrumentos para a formação inicial de professores de inglês. 2012. 458 f. Tese (Doutorado em Estudos da Linguagem) - Universidade Estadual de Londrina, 2012.

TONELLI, J. R. A. Histórias infantis no ensino da língua inglesa para crianças. 2005. Dissertação (Mestrado em Estudos da Linguagem) - Universidade Estadual de Londrina, Londrina, 2005.

A “dislexia" e o ensino-aprendizagem da língua inglesa. 2012. 574F. Tese (Doutorado em Estudos da Linguagem) - Universidade Estadual de Londrina, Londrina, 2012. 